\title{
Effect of Ultrasonic Electro-Chemical Polishing Parameters on Surface Roughness and Material Removal Rate of Medical Grade Cobalt Chromium Alloy
}

\author{
Is Prima Nanda ${ }^{\#}$, Muhammad Hafiz Jahare ${ }^{*}$, Mohd Hasbullah Idris ${ }^{*}$, Mohd Hazwan Hassim*, \\ Andril Arafat ${ }^{\$}$ \\ ${ }^{\#}$ Department of Mechanical Engineering, Faculty of Engineering, Universitas Andalas, Padang, 25163, Sumatera Barat, Indonesia \\ E-mail: isprimananda@eng.unand.ac.id
}

*Faculty of Mechanical Engineering, Universiti Teknologi Malaysia, UTM Skudai, 81310, Johor, Malaysia

E-mail: hafizjahare@gmail.com, hasbullah@fkm.utm.my,hzwn_sim@yahoo.com

${ }^{\$}$ Department of Mechanical Engineering, Faculty of Engineering, Universitas Negeri Padang, Padang 25131, Sumatera Barat, Indonesia E-mail: arafat@ft.unp.ac.id

\begin{abstract}
The fabrication of prosthesis from superalloys in bio-medical field is a challenging task as a result of strict tolerance requirement in surface finish. Precision surface finish is desired to avoid biocompatibility issue resulting from poor surface finish. Such surface finish requirement can be achieved by using Electro-Chemical Polishing (ECP) process. This research investigated the effect of applying ultrasonic vibration on ECP with process parameters, namely current $(0.5 \mathrm{~A}-2.5 \mathrm{~A})$ and time $(2 \mathrm{~min}-10 \mathrm{~min})$ on the surface roughness (Ra) and material removal rate (MRR) of cobalt chromium molybdenum (CoCrMo). The experiments were conducted using ECP and ultrasonic assisted ECP (UECP) processes whereby phosphoric acid (H3PO4) and SS 304 steel were used as electrolyte and electrode respectively. The result showed an increasing trend of MRR and Ra as the time and current increased in both processes. It was also found that ultrasonic assisted ECP at current $(2.5 \mathrm{~A})$ and time $(30 \mathrm{~min})$ recorded the highest MRR $(0.047$ $\mathrm{g} / \mathrm{min})$ and the lowest $\mathrm{Ra}(2.139 \mu \mathrm{m})$.
\end{abstract}

Keywords - Prosthesis; ECP; UECP; Phosphoric acid; CoCrMo.

\section{INTRODUCTION}

A medical implant such as prosthetic is a replacement for missing human structure. Since it was first introduced, prosthetic fabrication continues to expand along with the introduction of new materials and processing technologies. Nonetheless, the main contribution is occupied by the rapid growth of aged people population ratio [1]. Materials such as titanium alloys, stainless steel, and cobalt chromium alloys are the preferable material for permanent prosthetic application in recent days. However, prosthetic fabrication requires strict tolerance requirement in the surface finish in order to promote positive interaction between bones and implant. The condition of the implant surfaces also can encourage cell attachment [3]. The improper surface finish can cause implant degradation or implant failure at worst [4]. Hence, the requirement is to produce prosthetic with naturally low surface roughness and polished surface with a glossy appearance.

As far back as 1940's, corrosion and thermal fatigue resistant as well as high strength cobalt-based alloys was first introduced to serve as gas turbines. Since the last decade, Cobalt-based alloys are being deployed as medical implants based on its biocompatibility and excellent corrosion resistance performance [5]

Electrochemical polishing (ECP) is recognized as one of the processes that can accomplish the surface finish requirement. This process acknowledges interaction enhancement for both human tissue and implant material besides preventing platelet and endothelial cell adhesion that can cause thrombosis [6]. The material removal rate from electrochemical polishing is based on Law of Electrolysis by Faraday, as depicted in Equation 2 [6]

$$
\text { Wloss }=I t M / n F
$$


Where, Wloss is the material loss in total, $\mathrm{n}$ represents the valence electron of the metal ion, F represents the Faraday's constant, $\mathrm{M}$ is anode's molecular weight, $\mathrm{I}$ is the processing current, and $\mathrm{T}$ dictates polishing time.

Inconsideration of the constant variables, a total material loss for electrochemical polishing are influenced by both polishing time (t) and process current (I). In other words, the Electro-chemical polishing process provides an anodic polarization on a metallic surface in the selected electrolyte environment. The principle of anodic polarizing is based on anodic leveling that is generated by the dissolution rate's difference in peak and valleys on the surface of the particular rough metal and anodic brightening where dissolution rate is affected by the metal microstructure. The combination of these factors above thus creates a smooth and bright electrochemically polished surface [6].

Polarization curve occurred at the dissolution of anode resulted from the close contact of tool electrode and workpiece along with the increment of the applied current. Figure 1 illustrates the polarization curve of electro-chemical polishing. At anode potentials $\mathrm{AB}$; etching of the metal surface occurs. The smaller region $\mathrm{BC}$ indicates the probability of anode oxide film formation. Starting from $\mathrm{C}$ to $\mathrm{D}$ is the "Plateau region" where the electro-chemical polishing action occurs as depicted by constant current density along with voltage increment. Surface defects such as pits are often related to over exposure of electro-chemical polishing process with the high current application. As a result, the "Plateau region" current is preferable.

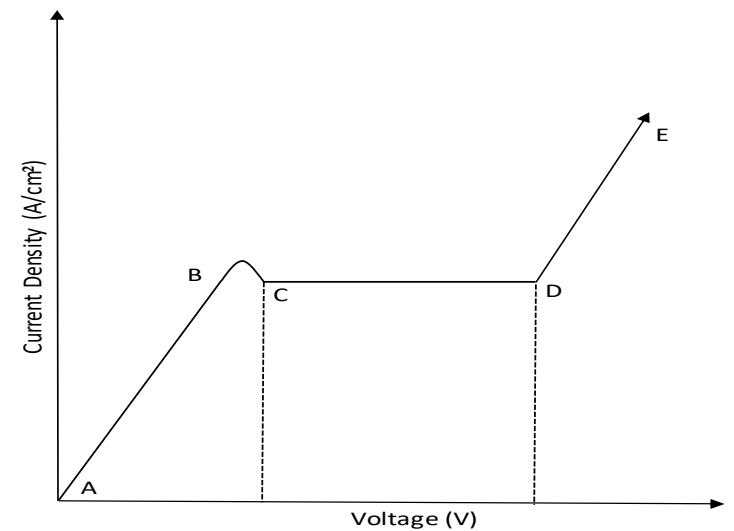

Fig. 1 Polarization curve of electro-chemical polishing. AB corrosion, dissolution (etching), $\mathrm{BC}$ passive, $\mathrm{CD}$ actual electro-chemical polishing, $\mathrm{DE}$ pitting

Electro-chemical polishing offers many technical advantages such as outstanding reflectance, higher corrosion resistance, better magnetic susceptibility, and reduction in coefficient of friction [7]. The performance of this process was reported by past researches on polishing Titanium alloy [8] and 316L stainless steel electro-chemically [9].

Improvement in process performance can be achieved by the introduction of ultrasonic vibration onto one particular process as shown in Figure 2. The benefits of adding ultrasonic vibration onto both non-conventional and conventional manufacturing processes had been reported by previous researchers. Such benefits include lower cutting force, reduced tool wear, a substantial increase in material removal rate, and enhanced surface finish [10]-[12]. Mwangi et al. [11] and Gunawan et al. [12] found that the ultrasonic vibration had successfully enhanced the Electro-Discharge Machining (EDM) capability. While the previous worked on AlSiC metal matrix composite and the latter SS 304 stainless steel, both highlighted on improved material removal rate and better surface roughness. Miyake et al. [13] on the other hand observed the application of low-frequency vibration on the feed rate of SUS 304 turning process. They found that the applied low-frequency vibration could prevent chip entanglement and better control of the cutting force. Based on the positive results, applying ultrasonic vibration on one particular process could increase the process performance in general. Nonetheless, the performance comparison between ECP and ultrasonic vibration assisted ECP on implant materials have not been covered extensively.

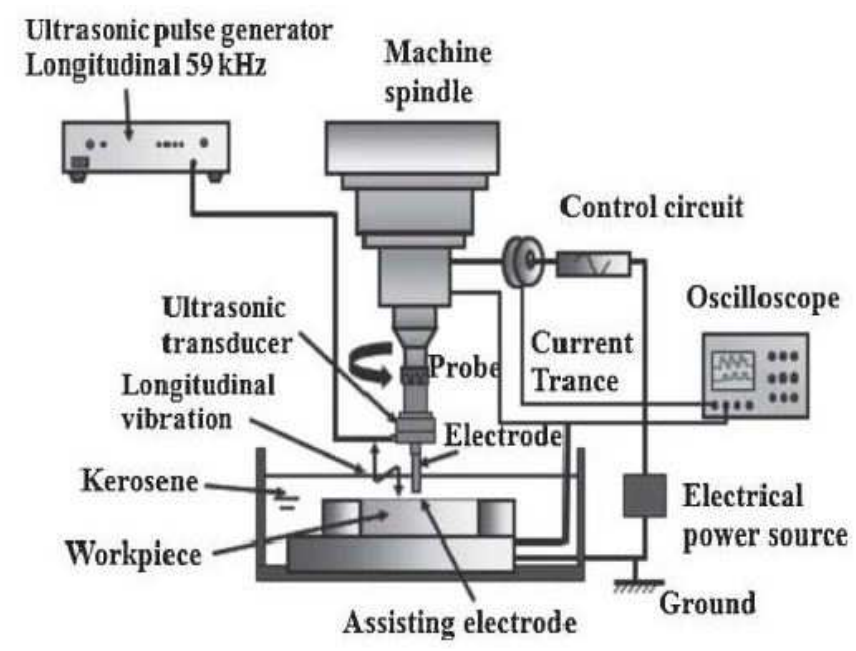

Fig. 2 Schematic diagram of ultrasonic assisted EDM process [12]

\section{MATERIAL AND METHOD}

In this study, medical grade cobalt chromium alloy; cobalt chromium molybdenum (CoCrMo) was chosen as work samples. The chemical composition of CoCrMo is shown in Table 1.

TABLE I

Chemical Composition of CoBAlt Chrome Molybdenum

\begin{tabular}{|l|l|}
\hline Element & Mass (\%) \\
\hline $\mathrm{Cr}$ & 30.00 \\
$\mathrm{Mo}$ & 7.00 \\
$\mathrm{Ni}$ & 0.50 \\
$\mathrm{Fe}$ & 0.75 \\
$\mathrm{C}$ & 0.35 \\
$\mathrm{Si}$ & 1.00 \\
$\mathrm{Mn}$ & 1.00 \\
$\mathrm{~W}$ & 0.02 \\
$\mathrm{P}$ & 0.02 \\
$\mathrm{~S}$ & 0.01 \\
$\mathrm{~N}$ & 0.25 \\
$\mathrm{Al}$ & 0.01 \\
$\mathrm{Ti}$ & 0.10 \\
$\mathrm{~B}$ & 0.01 \\
$\mathrm{Co}$ & Balance \\
\hline
\end{tabular}




\section{A. Samples Preparation}

Samples preparation include were machined into a rectangular bar of $70 \mathrm{~mm} \times 5 \mathrm{~mm} \times 5 \mathrm{~mm}$ using Sodick AQ537L CNC wire cut machine as shown in Figure 3. Mechanical polish at constant force was applied to all samples using with 800 grit $\mathrm{SiC}$ paper. Distilled water was occupied as coolant and lubricant. Afterward, the samples were cleaned using ultrasonic vibration with acetone bath for 5 minutes followed with distilled water before air dried.

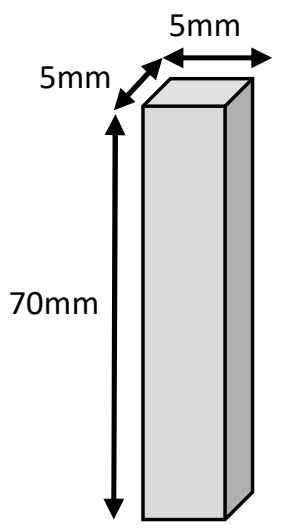

Fig. 3 Samples dimension prepared for ECP and UECP experiments

\section{B. Experimental Runs and Analysis}

A total of 18 experimental runs were performed to evaluate both ECP process and ultrasonic assisted ECP process. Controlled parameters selected are shown in table 2 based on the work by Hokuto Aihara [6]. Fixed parameters were limited to Phosphoric acid (H3SO4) of $15 \%$ concentration as an electrolyte, SS 304 as electrode and temperature was set at room temperature throughout the entire experiments. Experimental configuration for both processes are depicted in schematic Figure 4.

TABLE II

PROCESS CONTROLLED PARAMETERS

\begin{tabular}{|l|l|l|l|}
\hline Parameters & \multicolumn{3}{|c|}{ Range } \\
\hline Current (A) & $\begin{array}{l}0.12 \\
2\end{array}$ & $\begin{array}{l}0.39 \\
6\end{array}$ & $\begin{array}{l}0.68 \\
10\end{array}$ \\
Time (min) & 2 & & \\
\hline
\end{tabular}

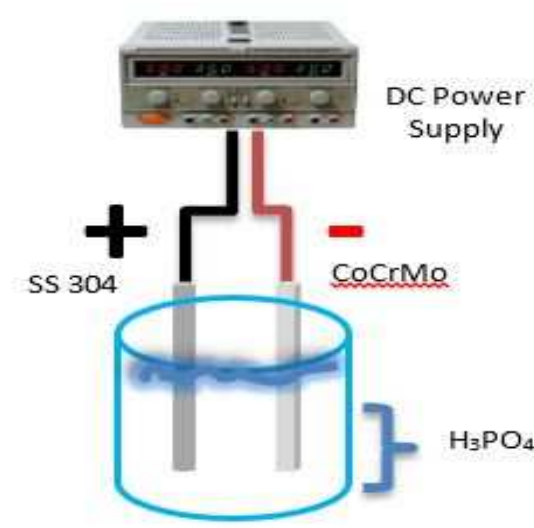

Fig. 4(a): ECP experimental configuration

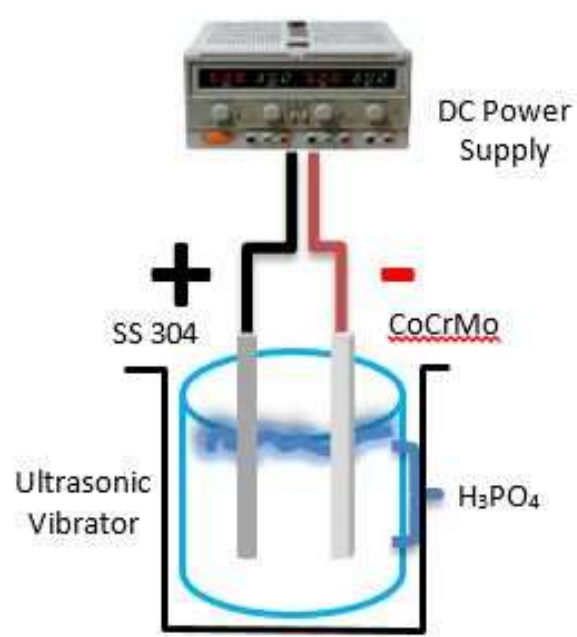

Fig. 4(b): UECP experimental configuration

Material removal rate calculation was based on weight loss of the samples acquired using Precisa balance. Samples weight measurement were performed during the process took place and machining time was taken using a digital stopwatch. The following formula represents MRR calculation:

$$
M R R=(X b-X a) / t
$$

Where MRR is denoted in $\mathrm{g} / \mathrm{min}, \mathrm{Xb}(\mathrm{g})$ is the initial sample's weight before cutting process, $\mathrm{Xa}(\mathrm{g})$ is the post sample's weight after cutting, and $t$ (min) represents machining time.

Surface roughness measurement was taken 5 times and averaged on each sample based on ASTM F2791-15 standard [14]. All measurement were performed using Mitutoyo Form Tracer CS-5000.

\section{RESULTS AND DISCUSSION}

The result of the experiment for both ECP and UECP are shown in table 3 . The result suggested that the UECP process is likely to give a higher value of MRR and lower Ra value respectively. Advantages of applying ultrasonic vibration have been reported by past researchers like Kobayashi et al. [10] which deployed an ultrasonic assisted polishing method to treat silicon wafer edge and correspondingly developed an experimental apparatus with ultrasonic elliptic vibration pad holder. They found that the method had successfully improved the surface roughness of wafer edges by $31.7 \%$ as compared to the wafer edges polished without ultrasonic action. 
TABLE III

SURFACE ROUGHNESS AND MRR RESULT FOR BOTH ECP AND UECP PROCESSES

\begin{tabular}{|c|c|c|c|c|c|}
\hline ECP & $\begin{array}{l}1 \\
2 \\
3 \\
4 \\
5 \\
6 \\
7 \\
8 \\
9\end{array}$ & $\begin{array}{l}0.12 \\
0.39 \\
0.68 \\
0.12 \\
0.39 \\
0.68 \\
0.12 \\
0.39 \\
0.68\end{array}$ & $\begin{array}{c}2 \\
2 \\
2 \\
6 \\
6 \\
6 \\
10 \\
10 \\
10\end{array}$ & $\begin{array}{c}4.82 \\
6.63 \\
7.23 \\
6.24 \\
8.57 \\
8.76 \\
8.35 \\
10.04 \\
10.84\end{array}$ & $\begin{array}{l}2.6528 \\
2.5665 \\
2.4825 \\
2.4788 \\
2.4113 \\
2.3290 \\
2.4168 \\
2.3014 \\
2.2945\end{array}$ \\
\hline
\end{tabular}

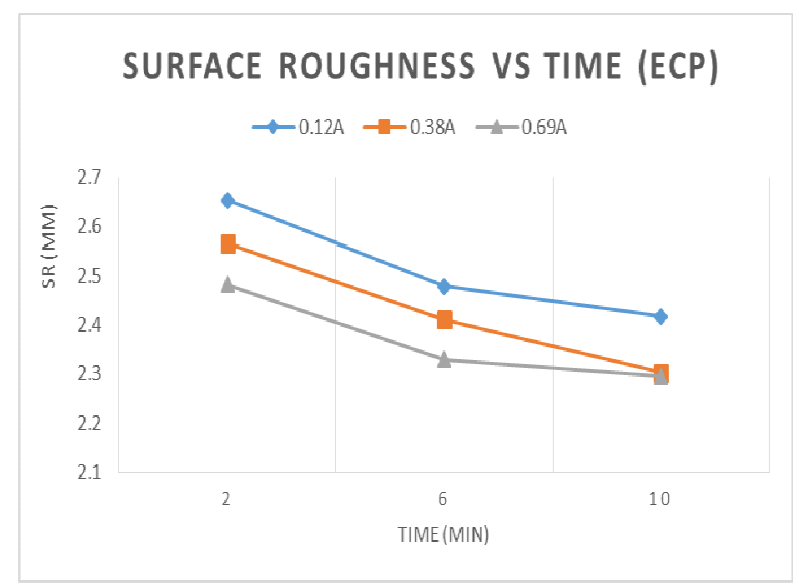

(a)

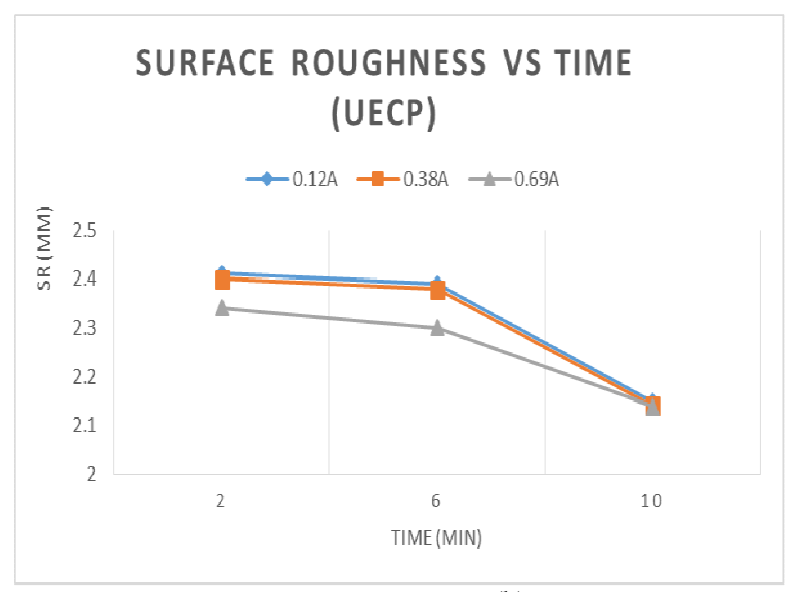

(b)

Fig. 5 Surface roughness plots against time from two different electro-chemical polishing approach a) ECP b) UECP

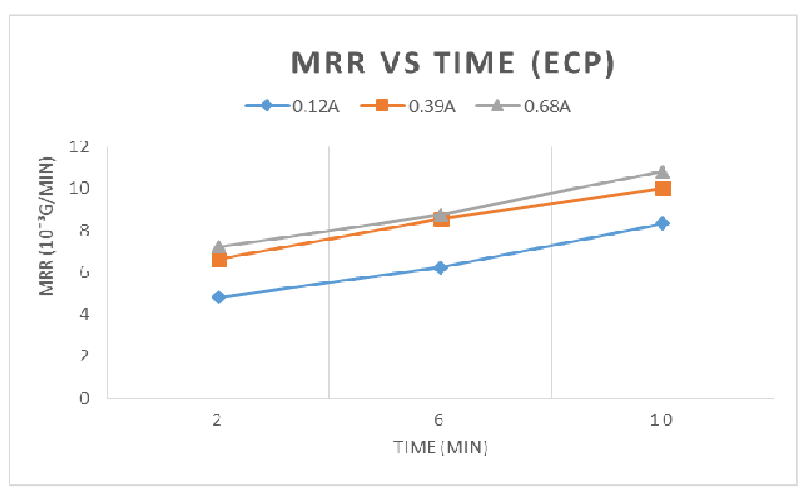

(a)

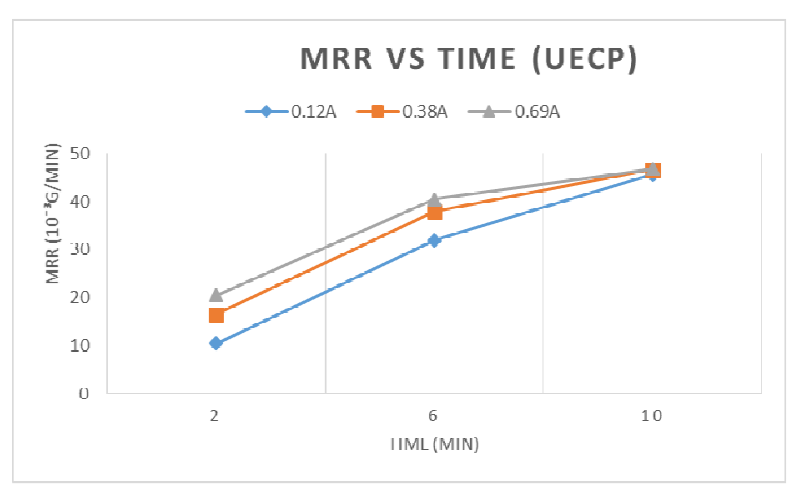

(b)

Fig. 6 MRR plots against time from two different electro-chemical polishing approach a) ECP b) UECP 


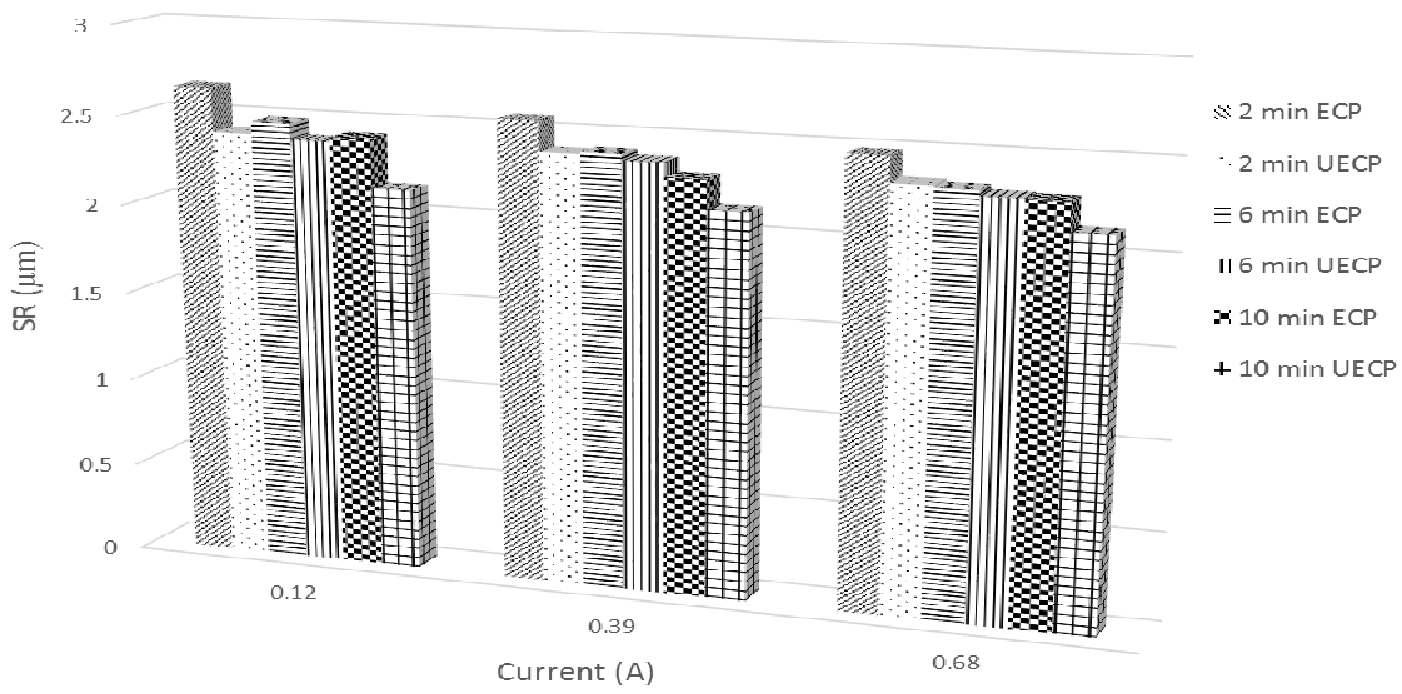

Fig. 7 Surface roughness trend of ECP and UECP

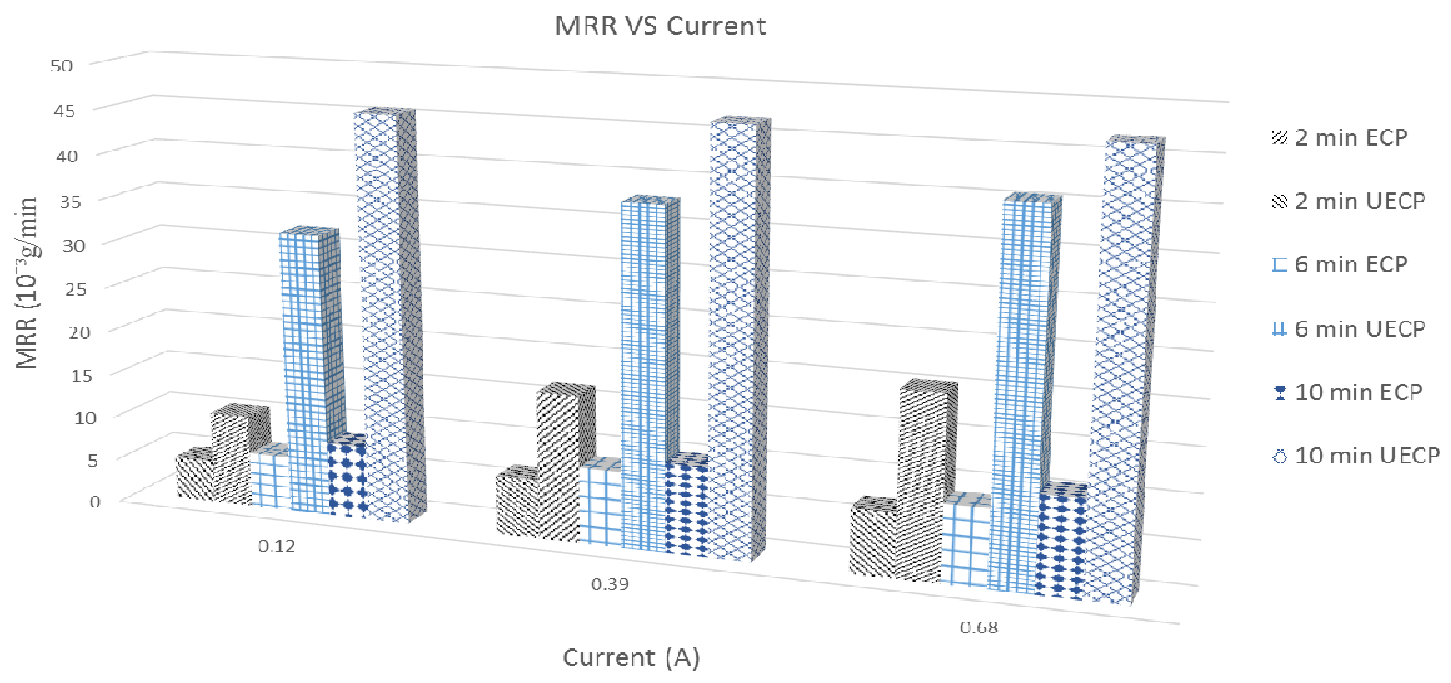

Fig. 8 MRR Trend comparison between ECP and UECP at different processing time

\section{A. Surface roughness}

The surface roughness of CoCrMo was considerably reduced as ultrasonic vibration was introduced to the process. The lowest SR value achieved was $2.1392 \mu \mathrm{m}$ at current $(0.69 \mathrm{~A})$ and time (10min), thus given approximately $7 \%$ improvement compared to normal ECP process. As depicted in figure 5(a) and 5(b), although the value of surface roughness was somewhat reduced by a small margin at lowest and middle parameter setting, yet at highest current (0.69A) and longest time setting (10 $\mathrm{min})$, surface roughness was fairly reduced for both process. As explained by Machado and Savi [15], both current application and time allocation significantly influenced the nature of surface characteristics.

The surface roughness saw a reduction trend at increasing current value. As shown in Figure 7, the highest surface roughness was obtained at the lowest current setting of
$0.12 \mathrm{~A}$. Then, the value was reduced until the lowest surface roughness obtained at the highest current setting of $0.69 \mathrm{~A}$.

The reduction in surface roughness value was due to the electro-chemical polishing effect. Such effect occurred when enough current is applied to the anode which subsequently increases the anode potential at the current plateau and insulates the anodic film. The anodic film then covers the lower peaks and valleys on one particular surface thus preventing dissolution while higher peaks which protruded above the anodic film which attain higher charge concentration dissolve more readily [6]. Lin and $\mathrm{Hu}$ [16] reported that reduction in process current from 1.0 to 0.5 $\mathrm{A} / \mathrm{cm}$ contributed to an increase in the average surface roughness. Nonetheless, the same condition was also detected on the surface roughness as the bath temperature increased from $30^{\circ} \mathrm{C}$ to $70^{\circ} \mathrm{C}$. Improvement on surface roughness for UECP was expected based on the result of previous researches on other manufacturing route process performance. 


\section{B. Material Removal Rate}

The material removal rate of CoCrMo was practically increased on ECP and UECP processes. As shown in figure 6(a) and 5(b), the UECP process recorded higher MRR even at the lowest current setting $(0.12 \mathrm{~A})$, unlike ECP process which could be justified as exceptionally lower. Before 0.39A current setting, the MRR of UECP also increased linearly. Towards the highest current setting (0.69A), the increment was somewhat modest.

On the other hand, the MRR of ECP process increased linearly towards the highest current setting (0.69A) although the rate is much less as compared to the UECP process. Figure 8 further emphasizes the huge difference in material removal rate between ECP and UECP. At different current level, UECP recorded almost two times better material removal rate and therefore highlighted the advantage of applying ultrasonic vibration on performing electro-chemical polishing.

As explained by Faraday's Law of Electrolysis, the material removal rate from both ECP and UECP processes are significantly regulated by current and time. As depicted by Figure 8 , the material removal rate of both processes recorded an increasing pattern concerning time. The evidence suggested that ultrasonic assisted electro-chemical polishing could generate more than twice material removal rate capability as compared to normal electrochemical polishing process.

\section{CONCLUSIONS}

This research intended to investigate the effect of ECP and UECP with process parameters; current (A) and time (min) on the MRR and surface roughness of CoCrMo samples. Higher MRR and noticeably lower surface roughness reduction could be achieved by using the UECP process compared to ECP. Highest MRR and surface roughness $(\mathrm{Ra})$ recorded was $0.047 \mathrm{~g} / \mathrm{min}$ and $2.139 \mu \mathrm{m}$ respectively at parameter setting of current $(0.69 \mathrm{~A})$ and time (10min)

\section{NOMENCLATURE}

$\begin{array}{lll}\mathrm{MRR} & \text { material removal rate } & 10^{-3} \mathrm{~g} / \mathrm{min} \\ \mathrm{Ra} & \text { length co-ordinate } & \mu \mathrm{m}\end{array}$

\section{Subscripts}

$\mathrm{W}_{\text {loss }}$ Total material lost

$\mathrm{n} \quad$ Valence of metal ion

F Faraday's constant

M Molecular weight of the anode

I Process currently

$\mathrm{T} \quad$ Processing time

$\mathrm{X}_{\mathrm{b}} \quad$ Initial sample's weight

$\mathrm{X}_{\mathrm{a}} \quad$ Post sample's weight

$\mathrm{t}$ Machining time

\section{ACKNOWLEDGMENT}

We would like to thank all the personnel involved throughout this entire research and very much grateful for all the advice and knowledge shared. The authors also wish to place their sincere thanks to Faculty of Engineering at Universitas Andalas (project fund with contract number 017/UN.16.09.D/PL/2018), Faculty of Mechanical at Universiti Teknologi Malaysia and Faculty of Engineering at Universitas Negeri Padang.

\section{REFERENCES}

[1] Abdul Aziz, Gunawarman, Jon Affi, "The Effects of Short-Time Solution Treatment and Short-Time Aging on Mechanical Properties of Ti-6Al-4V for Orthopaedic Applications," Int. J. on Advanced Science Engineering Information Technology, vol. 5, pp. 329-334, 2015.

[2] Anwesa Barman, Manas Dias, "Nano-finishing of bio-titanium alloy to generate different morphologies by changing magnetorheological polishing fluid compositions," Precision Engineering, vol. 51, pp. 145-152, 2018

[3] L. Ostrovska, L. Vistejnova, J. Dzugan, P. Slama, T. Kubina, E. Ukraintsev. "Biological evaluation of ultra-fine titanium with improved mechanical strength for dental implant engineering," $J$. Material Science, vol. 51, pp. 97-110, 2016.

[4] R. Dmitry, P. Megha, J.J. Joshua, A. W. Markus, H.J. Nadim, M.T. Mathew. "In vitro simulation of fretting-corrosion in hip implant modular junctions: The influence of $\mathrm{pH}$," Medical Engineering and Physics, vol. 52, pp. 1-9, 2018.

[5] P. Crook, Cobalt and Cobalt Alloys, ASM Handbook Volume 2 Properties and Selection: Nonferrous Alloys and Special-Purpose Materials: ASM International, 1990

[6] Hokuto Aihara, Surface and biocompatibility study of electropolished Co-Cr Alloy L605, Master thesis, San Jose State University, 2009.

[7] I.P. Konstantin, S.D. Stojan, and N.G. Branimir, Fundamental Aspects of Electrometallurgy, New York: Kluwer Academic Publishers, 2002.

[8] K. Donghyun, S. Kyungsik, S. Dahye, K. Yonghwan, C. Wonsub, "Effect of added ethanol in ethylene glycol- $\mathrm{NaCl}$ electrolyte on titanium electropolishing," Corrosion Science, vol. 98, pp. 494- 499, 2015.

[9] H. Yaolei, M. Jinna, P. Qunjia, H. En-Hou, K. Wei, "Effect of electropolishing on corrosion of nuclear grade 316L stainless steel in deaerated high-temperature water," Corrosion Science, vol. 112, pp. 625-634, 2016

[10] N. Kobayashi, Y. Wu, M. Nomura, T. Sato, "Precision treatment of silicon wafer edge utilizing ultrasonically assisted polishing technique," Journal of Materials Processing Technology, vol. 201, pp. 531-535, May 2008.

[11] J.W. Mwangi, B.W. Ikua, G.N. Nyakoc, H. Zeidler, S.K. Kabini, "Effect of low-Frequency Vibration In Electrical Discharge Machining of AlSiC Metal Matrix Composite, "Journal of Sustainable Research in Engineering, vol. 1, pp. 45-50, 2014.

[12] Gunawan Setia Prihandana, Muslim Mahardika, M. Hamdi, Kimiyuki Mitsui, "Effect of low-frequency vibration on the workpiece in EDM processes," Journal of Mechanical Science and Technology, vol 25, pp. 1231-1234, 2011.

[13] A. Miyake, H. Sasahara, M. Muramatsu, K. Noguchi, A. Kitakaze, S. Katoh, K. Sannomiya, T. Nakaya, "Effect of low-frequency vibration applied to feed direction on turning process," Proc. of ISFA International Symposium of Flexible Automation, Cleveland, Ohio, U.S.A, 2016, pp. 356-358.

[14] ASTM F2791 - 15, Standard Guide for Assessment of Surface Texture of Non-Porous Biomaterials in Two Dimensions. ASTM International, 2015.

[15] L.G. Machado, M. A. Savi, "Medical Applications of Shape Memory Alloys," Brazilian Journal of Medical and Biological Research, vol. 36, pp. 683-691, 2003.

[16] C.-C. Lin and C.-C. Hu, "Electropolishing fo 304 Stainless Steel: Surface Roughness Control Using Experimental Design Strategies and Summarized Electropolishing Model," Electrochim Acta, vol. 63, pp. 3356-3363, 2008. 